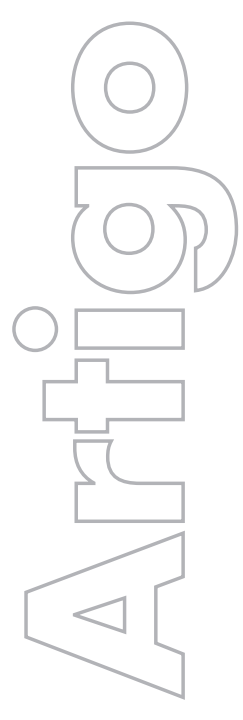

revista

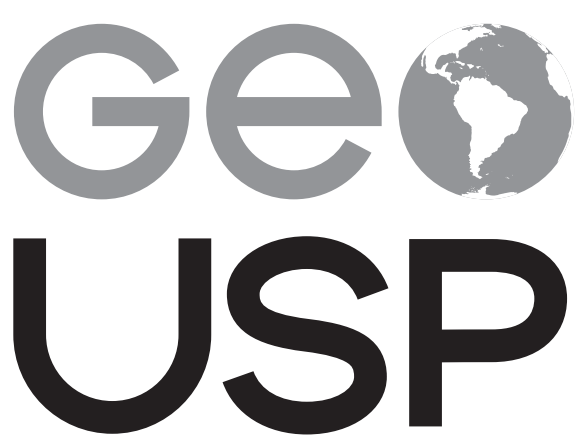

espaço e tempo

Volume $19 \cdot n^{\circ} 3(2015)$
Discurso de atores sociais frente o uso e acesso aos bens naturais: o caso dos pescadores artesanais de Matinhos-PR

\section{Ana Clara Giraldi Costa UFPR Afonso Takao Murata UFPR \\ p. $535-550$}

Como citar este artigo:

COSTA, A. C. G.; MURATA, A. T. Discurso de atores sociais frente o uso e acesso aos bens naturais: o caso dos pescadores artesanais de Matinhos-PR. Geousp Espaço e Tempo (Online), v. 19, n. 3, p. 535-550, mês. 2016. ISSN 2179-0892.

Disponívelem: URL:http://www.revistas.usp.br/geousp/ article/view/89181. DOI: http://dx.doi.org/10.11606/ issn.2179-0892.geousp.2015.89181.

\section{(c) (i) (5)}

Este artigo está licenciado sob a Creative Commons Attribution 4.0 License. 


\title{
Discurso de atores sociais frente o uso e acesso aos bens naturais: o caso dos pescadores artesanais de Matinhos-PR
}

\section{Resumo}

objetivo deste artigo é refletir sobre o discurso de grupos historicamente excluídos dos processos de desenvolvimento e que atualmente passam por conflitos socioambientais devido ao uso e a acesso aos bens naturais. Destaca-se o caso dos pescadores artesanais do município de Matinhos-PR, comunidade que vem passando nos últimos anos por inúmeros conflitos de ordem ambiental, entre eles, um relativo à implantação de uma unidade de conservação de proteção integral que vem impedindo o uso e o acesso consuetudinário aos recursos pesqueiros da região.

Palavras-chave: Populações tradicionais. Conflitos socioambientais. Unidades de conservação. Território. Reprodução social.

Speech of stakeholders across the use and access to natural resources: the case of artisanal fishermen of Matinhos-PR

\begin{abstract}
This research was the objective to reflect how speech groups historically excluded from development processes has and that currently go through socioenvironmental conflicts due to the use and access to natural resources in some Latin American countries. Highlighting, the case of artisanal fishermen of Matinhos town, Paraná state, community that comes through in recent years by numerous environmental conflicts, among them a conflict on the implementation of an Integral Protection Conservation Unit, which has prevented the use and customary access of fishery resources in the region.
\end{abstract}

Keywords: Traditional populations. Socio-environmental conflicts. Protected Areas. Territory. Social reproduction. 


\section{Introdução}

As estratégias de desenvolvimento e modernização que os países latino-americanos adotaram a partir da Segunda Guerra Mundial impactaram de maneira significativa a vida de muitos povos, comunidades e grupos sociais que estavam na contracorrente desse processo. Assim, por muito tempo, essas sociedades permaneceram esquecidas, marginalizadas e muitas vezes expropriadas de seus modos de vida.

Entretanto, essas sociedades assumem hoje papel relevante na gestão dos territórios. Como lembra Zibechi (2010), os marginalizados são os protagonistas do último ciclo de lutas contra os projetos extrativos de larga escala e pelos direitos sociais, políticos e civis, representando hoje, os atores mais destacados do mundo dos oprimidos. Nesses grupos estão inseridos povos e comunidades tradicionais ${ }^{1}$ e trabalhadores rurais sem terra, entre outros, que adquiriram tamanha importância que já não se pode mais fazer política nem governar sem considerar sua existência e sua importância na formulação de políticas públicas.

Nesse sentido, precisam ser estudadas à luz das relações com esses processos de desenvolvimento e principalmente ter voz para colocar suas demandas. Assim, este artigo tem como objetivo fazer uma reflexão sobre como tem se dado o discurso desses grupos historicamente excluídos dos processos de desenvolvimento, e que passam hoje por conflitos ambientais pelo uso e acesso aos bens naturais, destacando o caso da comunidade de pesca artesanal do município de Matinhos, no litoral paranaense.

$\bigcirc$ artigo está estruturado em três partes. A primeira busca relacionar os processos de desenvolvimento com os conflitos socioambientais eclodidos nas últimas décadas. A segunda enfatiza um panorama histórico de como se tem dado a mobilização social e os discursos dos povos e comunidades tradicionais frente ao uso costumeiro dos bens naturais expropriados até então pelos processos de desenvolvimento e suas estratégias. Por fim, uma discussão do caso da comunidade de pesca artesanal do município de Matinhos, que tem passado por alguns conflitos de ordem ambiental, destacando o ligado à implantação de uma unidade de conservação de proteção integral, que vem impedindo o uso e acesso consuetudinário dos recursos pesqueiros da região.

Para tanto, aplica-se um instrumental teórico latino-americano de autores que estão à frente desses movimentos sociais, ora na militância, ora em projetos de investigação pautados no diálogo e na ação conjunta com esses atores. Acreditamos, assim como Grosfoguel (2008), na necessidade de falar do Sul a partir do Sul e da cosmovisão de pensadores críticos do Sul, que pensam sob perspectivas de corpos e lugares étnico-raciais subalternizados.

Da mesma maneira, os dados empíricos apresentados resultam de um processo de pesquisa alternativa, denominada aqui pesquisa participante (PP). Esta pesquisa tendo como pressuposto central a participação e o envolvimento entre pesquisadores e pesquisados, está sendo construída através do diálogo e ação conjunta com os pescadores artesanais de Matinhos.

1 Entendemos por povos e comunidades tradicionais grupos humanos diferenciados do ponto de vista cultural que reproduzem historicamente seus modos de vida com base na cooperação social e em relações próprias com a natureza. Exemplos empíricos de populações tradicionais são as comunidades caiçaras, os sitiantes e roceiros, as comunidades quilombolas, as comunidades ribeirinhas, os pescadores artesanais e os grupos extrativistas e indígenas (Diegues, 2001). 


\section{Desenvolvimento e conflitos socioambientais}

Nos países do chamado Terceiro Mundo, como o Brasil, as estratégias de desenvolvimento lideradas por agências internacionais, entre elas, o Banco Mundial e Fundo Monetário Internacional visavam a estruturação e reestruturação de instituições sociais, assim como investimentos em infraestruturas de transporte, energia e de indústrias de base como polos de desenvolvimento para a aceleração do crescimento econômico. Após uma fase inicial era esperado que essas estratégias proporcionassem, quase que automaticamente, a inclusão social através da geração de renda e de emprego, seguida da instalação do Estado de bem-estar (Zhouri; Laschefski, 2010).

Para Furtado (1983) o sentido de desenvolvimento representava apenas a ideia de crescimento, produtividade e industrialização, isto é, o crescimento econômico como sinônimo de desenvolvimento. Dessa maneira, ao analisar essas estratégias à luz de indicadores sociais, ambientais, éticos e políticos, é possível detectar sérios problemas.

Já Souza (2002) alerta que a conceituação do termo "desenvolvimento" contém equívocos enraizados através de discursos ideológicos/políticos. Para o autor, o termo foi usualmente encarado como "desenvolvimento econômico" pouco importando outros problemas, como aqueles ligados aos aspectos sociais e ambientais.

Assim, como bem lembra Escobar (2005), à medida que passamos para o século atual, os problemas desse desenvolvimento seguem sendo desafiantes. A expropriação e supressão de camponeses e de suas atividades domésticas e de produção solidária, o desemprego estrutural nos centros urbanos com a geração de uma massa de proletariados destituídos de propriedade, os mecanismos de exploração territorial de classe e de recursos e os mais variados casos de conflitos fundiários (Brandão, 2010; Zhouri; Laschefski, 2010), expressam segundo Escobar (2005), as guerras brutais e deslocamentos massivos com o propósito de abrir regiões inteiras para este capital transnacional, sobretudo em busca dos chamados recursos naturais.

O desenvolvimento que se procedeu criou e continua criando conflitos de inúmeras ordens: econômica, política, social, cultural e ambiental, principalmente porque usa de artifícios ora de controle e regulação social, ora de acumulação do capital. Desde uma perspectiva subjetiva, estes e muitos outros mecanismos sustentados na maioria das vezes pelo Estado e pelo projeto desenvolvimentista, acabam por promover, como ressalta Escobar (2005), identidades fragmentadas, que transformam culturas de solidariedade em culturas de destruição.

Dessa maneira, no Brasil, os processos de desenvolvimento deixaram impressos no território e nas relações sociais formas mercantis, patrimonialistas e financeirizadas coexistindo com classes destituídas de direitos e propriedade (Brandão, 2010). Sem contar, claro, com a tamanha destruição da riqueza natural desses países. Para Svampa (2011), em nome das vantagens comparativas ou da pura subordinação a ordem geopolítica mundial, foi reservado para a maioria dos países da América Latina o rol de exportador da natureza, sem considerar seus impactos desestruturastes sobre a população, nem os enormes efeitos socioambientais.

A fim de mitigar o modelo extrativo exportador capitalista, o Brasil tem adotado nas últimas décadas inúmeras políticas de compensação ambiental. A preservação da biodiversidade é compensada pela implantação de áreas naturais protegidas, entre elas, as unidades de conser- 
vação. Entretanto, o estabelecimento de categorias restritas à ocupação e à atividade humana, como os parques, ${ }^{2}$ tem dado margem a complexas situações de conflito socioambiental, seja pela expulsão e exclusão das populações residentes em tais áreas, seja pela restrição ao acesso e uso costumeiro dos recursos naturais contidos nelas.

Já Zhouri e Laschefski (2010) ressaltam que, no tocante à dimensão ambiental do desenvolvimento, emergiram ações de prevenção dos impactos através de meios técnicos, ou nos casos em que isso não fosse possível, a adoção de medidas de mitigação e compensação com o objetivo de conciliar os interesses econômicos e ambientais, moldando assim o modelo clássico de desenvolvimento. Ocorre, contudo, que esses interesses não convergiram com as demandas daqueles grupos e comunidades tradicionais que estavam na contracorrente dos processos de desenvolvimento.

Além disso, o modelo de desenvolvimento baseado em estratégias de eficiência energética, no desenvolvimento de novas mercadorias "ecologicamente corretas" e mecanismos de mercado como a certificação ambiental e o crédito de carbono, que representam a racionalidade produtiva e a chamada "modernização ecológica", continuam apontando para índices de desmatamento, mudanças climáticas e extinção de espécies cada vez mais altas. $\bigcirc$ quadro de poluição da terra, água e ar se agravaram ao passo que também a desigualdade social não diminuiu (Zhouri; Laschefski, 2010, p. 15).

Posto isto, os conflitos socioambientais são cada vez mais frequentes, sendo em parte consequência da debilidade na implementação das políticas e esquemas de gestão disponíveis para a regulação do uso e acesso dos recursos naturais (Vargas, 2007), como também pela crescente privatização de muitos bens antes partilhados por populações tradicionais e grupos sociais, pela incapacidade das políticas mitigatórias e compensatórias de proporcionar de fato melhoria social e ambiental, e claro, pelo modelo extrativo-exportador adotado.

Fica evidente, portanto, que o tipo de desenvolvimento imposto nas últimas décadas, bem como, suas respectivas políticas compensatórias não estabelecem mais uma opção, mas um fator conflitante na vida das sociedades subalternizadas. De acordo com Escobar (2005), a globalização econômica adquiriu tal potência que aparentemente relegou os debates sobre o meio ambiente a um plano inferior. Por outro lado, os movimentos sociais e a contínua pobreza mantêm na agenda assuntos sobre justiça ambiental e desenvolvimento.

Assim, a partir do final da década de 1980, identificam-se sensíveis mudanças na dinâmica política dos conflitos, sobretudo no que diz respeito ao surgimento de novas vozes, atores políticos e protagonistas na cena pública e nas arenas políticas (Cruz, 2013), principalmente pela intensificação da ingerência externa em questões de ordem política.

2 marco fundamental da estratégia de criação de áreas protegidas no mundo foi a implementação do Parque Nacional Yellowstone, nos EUA, em 1872. Segundo Diegues (2002), após a estratégia estadunidense, a criação de áreas naturais protegidas, sobretudo de caráter humano restrito, começou a se difundir em países como o Brasil nas primeiras décadas do século XX e, com ela, os conflitos envolvendo populações residentes começaram a se agravar. Estes se tornaram ainda mais sérios a partir da década de 1970, quando essas comunidades começaram a se organizar e, em muitos casos, resistir à expulsão ou à transferência de seus territórios ancestrais. 
Nesse universo, ganham destaque hoje no cenário os discursos desses grupos historicamente excluídos dos processos de desenvolvimento e que passam hoje por inúmeros casos de conflitos espaciais, distributivos e, sobretudo territoriais ${ }^{3}$ envolvendo os recursos naturais até então partilhados e utilizados de maneira consuetudinária.

\section{Mobilização social e discurso frente ao uso costumeiro dos bens naturais}

No fim da década de 1950, quando o Estado nacional desenvolvimentista começou a demonstrar suas primeiras fraquezas, devido principalmente a importante mudança na estrutura social com o declínio relativo da população rural, em consonância com o aumento da população urbana, as sociedades até então excluídas e marginalizadas voltaram a se manifestar como classes perigosas. Mais expressivamente a partir da década de 1980, o panorama político e social do mundo popular começou a tomar novas dimensões. Povos e comunidades tradicionais e mais tarde imigrantes rurais organizaram-se em movimentos autônomos. Esses novos atores deram vida a uma nova geração de organizações e promoveram mobilizações ${ }^{4}$ diferentes das anteriores, elaboraram novos discursos e práticas (Zibechi, 2010).

Nas décadas de 1970-80, se estrutura também um pensamento alternativo à corrente hegemônica sobre a questão territorial. Segundo Brandão (2007), o território até então hegemonizado por uma visão econômica, conservadora, estática e positivista vai perdendo espaço para a ideia do território como uma produção social, à luz da análise dos conflitos e das lutas que se travam em torno desse ambiente construído socialmente.

território assume dessa maneira um papel central no discurso desses novos atores, assumindo segundo Cruz (2013, p. 119), uma dupla centralidade no contexto das lutas dos movimentos sociais, uma centralidade analítica e política, ou seja, como "categoria de análise" e como "categoria de práxis". Na primeira perspectiva, é possível verificar que o conceito de território vai sendo amplamente mobilizado em diversos campos disciplinares como uma categoria explicativa essencial para se pensar a realidade das lutas sociais das populações tradicionais.

Já como categoria de práxis, a palavra território funciona como um dispositivo de agenciamento político. Essa categoria é uma espécie de catalisador das energias e estratégias emancipatórias desses movimentos, ela está presente nas entrevistas, depoimentos e declarações de lideranças dos movimentos dos camponeses e dos povos e comunidades tradicionais (Cruz,

3 Zhouri e Laschefski (2010) consideram, para efeitos heurísticos, três tipos de conflito ambiental: distributivo, espacial e territorial. $\bigcirc$ cerne dos conflitos ambientais distributivos são a distribuição dos recursos, isto é, as desigualdades sociais em torno do acesso e do uso dos recursos naturais. Como exemplo, citam-se os conflitos sobre a água no espaço urbano, bem como os casos em torno da transposição do rio São Francisco. Os conflitos ambientais espaciais são os decorrentes de efeitos ou impactos ambientais que ultrapassam os limites entre os territórios de diversos agentes ou grupos sociais, tais como emissões gasosas, poluição da água etc. Por fim, os conflitos ambientais territoriais surgem quando se sobrepõem reivindicações de diversos segmentos sociais diferentes identidades e lógicas culturais no mesmo recorte espacial, como, por exemplo, área para a implantação de uma hidrelétrica ou uma unidade de conversão de proteção integral versus territorialidade de populações afetadas.

$4 \bigcirc$ ano de 1989 é considerado um marco da emergência de um conjunto de mobilizações e encontros de comunidades tradicionais, como o I Encontro de Povos Indígenas do Xingu, o I Encontro de Povos da Floresta, o Encontro dos Trabalhadores atingidos por Barragens, que deram origem a diversas formas de movimentos sociais e associações e começaram a lutar pela afirmação de territorialidades e identidades como elementos de resistência contra os que exploram e dominam, mas, sobretudo, como elementos de resistência de determinado modo de vida e de produção. Assim, as comunidades tradicionais se organizam, ganhando visibilidade e protagonismo, constituindo-se e se afirmando como sujeitos políticos (Cruz, 2013). 
2013). Segundo o autor, a partir desse momento, é cada vez mais comum e frequente na retórica das lutas sociais do campo o uso do conceito de território para referir-se às terras tradicionalmente ocupadas.

Diferentemente dos movimentos das épocas passadas, esses novos movimentos trazem como traço marcante uma grande diversidade de origens sociais, étnicas e culturais. Têm no centro de seus discursos uma politização da cultura e uma revalorização das memórias, tradições e saberes locais, reivindicando cidadania e justiça social que sejam capazes de pautar-se numa maior redistribuição material dos recursos e no reconhecimento das diferenças (Cruz, 2013).

Nesse sentido, reivindicam e propõem ainda, novas práticas de produção e comércio, baseadas na solidariedade e na reapropriação social da natureza. Segundo Cruz (2013), há em seus discursos uma intensa valorização material e simbólica do espaço, expresso através do papel que estes dão à terra, ao território e as territorialidades. $\bigcirc$ território torna-se então um condensador de direitos, pois as lutas por maior igualdade, pelo reconhecimento da diferença, bem como, a luta pelo direito à natureza e a um meio ambiente equilibrado se materializam no direito ao território.

Nessa linha de argumentação, Svampa (2011, p. 190) considera que o discurso e a dinâmica dessas lutas socioambientais dos povos e comunidades tradicionais podem ser denominados "giro ecoterritorial". Para a autora, o giro ecoterritorial é um conceito que consegue dar conta do modo como pensam e representam, desde a perspectiva das resistências coletivas, as atuais lutas socioambientais centradas na defesa da terra e do território. Tais discursos se caracterizam como tal, porque trazem à tona, de maneira coletiva, temas como bens comuns, justiça ambiental, e direito sobre a natureza.

Assim, o conceito de giro ecoterritorial tem forte identificação com o que os próprios atores chamam de movimento de justiça ambiental: refere-se à construção de marcos de ação coletiva que, segundo Maristella Svampa (2011, p. 191), "funcionan como estructuras de significación y esquemas de interpretación contestatarios o alternativos". Esses marcos contestatórios tendem a desenvolver uma importante capacidade mobilizadora e trazem à tona a subjetividade e as aspirações das lutas socioambientais.

Nesse sentido, a mobilização social e o discurso que se travam pelo uso e acesso aos bens naturais se pautam no direito a um ambiente seguro, livre e produtivo para todos, onde o meio ambiente é considerado em sua totalidade, incluindo suas dimensões ecológicas, físicas, políticas, sociais, estéticas e econômicas (Svampa, 2011), construídas socialmente no tempo e no espaço. Na realidade, segundo Svampa, esses discursos expressam a vontade que estes grupos têm em dizer não aos projetos extrativos de grande escala e as políticas ambientais compensatórias, que afetam fortemente as condições de vida dos setores mais vulneráveis.

No universo das políticas ambientais compensatórias, observa-se também outro tipo de discurso dos povos e comunidades tradicionais: o direito à natureza e ao uso dos bens naturais consuetudinariamente usados e partilhados que essas populações travam com categorias de unidades de conservação restritas à ocupação e à atividade humana, isto é, as unidades de conservação de proteção integral.

Esses discursos de direito à natureza e ao território se chocam com a visão preservacionista clássica do ambientalismo, que valoriza a natureza intocada e considera o ser humano como o devastador dela. Nesse contexto, após estratégias de desenvolvimento fracassadas 
que resultaram na devastação ambiental, juntamente com a força de órgãos e estudiosos preservacionistas, o país adotou, entre outros mecanismos, a criação de unidades de conservação (UC) como políticas de compensação ambiental.

A criação de UC é uma estratégia que se vem consolidando para proteger e manter os recursos ecossistêmicos e a diversidade biológica e também cultural. A discussão acerca da conservação da natureza com a criação de áreas de proteção integral versus territorialidade de populações humanas que usam tais espaços para sua reprodução simbólica e material é uma discussão antiga.

Medeiros (2005) relembra a longa história da tramitação até a aprovação do projeto que deu origem ao Sistema Nacional de Unidades de Conservação (Snuc) em 2000 e observou, naquele período, as posições conflituosas sobre a forma e os critérios de proteção da natureza entre socioambientalistas, preservacionistas e conservacionistas. Entre os pontos mais polêmicos das discussões, destacava-se justamente a questão das populações residentes e/ou que usufruíam dos recursos naturais desses lugares.

Para contemplar estratégias distintas de gestão dessas áreas, foi promulgada a Lei n. 9.985/2000, que versa sobre a criação de 12 categorias de unidades de conservação reunidas em dois grandes grupos: unidades de proteção integral e unidades de uso sustentável (Medeiros, 2005).

Segundo Medeiros (2005), o Snuc, criado a partir de pressões dos socioambientalistas, possibilitou o advento de novas categorias a partir de experiências originais desenvolvidas no país, como o caso das reservas extrativistas (Resex) e as reservas de desenvolvimento sustentável (RDS). Categorias estas que representaram, segundo o autor, um importante avanço na concepção de áreas protegidas no que diz respeito à inclusão social e econômica das populações que vivem dentro ou no entorno dessas áreas e sobrevivem de seus recursos.

Entretanto, apesar de o Brasil ter avançado muito no tema da proteção da natureza e das populações residentes e/ou usufruidoras dos recursos naturais instituindo essas categorias, persiste ainda hoje o descontentamento popular, seguido de casos de conflitos decorrentes da criação de UC, em especial as de proteção integral, como relatamos neste trabalho.

A instituição de categorias restritas ao uso e ocupação humana, bem como, a visão clássica do ambientalismo vão na contracorrente de grupos e populações tracionais que desenvolveram modos singulares de uso e apropriação simbólica e material da natureza.

Entretanto, independentemente de quem os apoia (corporações, elites econômicas ou Estado, em suas diversas políticas públicas) e das circunstâncias em que esses povos e comunidades lutam pelo direito à natureza, suas lutas defendem muito mais que a continuidade econômica de sua vida: defendem sua própria continuidade social e cultural.

De igual modo, observa-se que muitos dos movimentos não estão orientados apenas pela satisfação de suas necessidades materiais. Escobar (2005) ressalta que muitos desses grupos, povos e comunidades objetivam manter direitos culturais para continuar com suas práticas cotidianas e costumeiras ancestrais, para além das fronteiras culturais.

Nesse contexto, Macas (2014) pondera que essas lutas não trazem somente temas de reivindicação de nacionalidades originárias, mas trazem à tona estratégias de resistência à modernização e ao sistema que oprime e explora. 
Dessa maneira, hoje esses sujeitos ganham densidade e conteúdo pela afirmação de múltiplas formas de associação, como as colônias de pesca e os conselhos de seringueiros quilombolas, que ultrapassam o sentido estreito de organização sindical, incorporando fatores étnicos, critérios ecológicos, de gênero e de autodefinição coletiva (Cruz, 2013). Entretanto, o autor ressalta que, mais do que uma estratégia de discurso, ocorre o advento de categorias que se afirmam por meio da existência coletiva, politizando não apenas as nomeações da vida cotidiana, mas também as práticas rotineiras de uso da terra.

\section{O estabelecimento do Parque Nacional Marinho das Ilhas dos Currais e o discurso dos pescadores artesanais de Matinhos-PR}

A comunidade de pesca artesanal, objeto deste artigo, está localizada na região central do município de Matinhos-PR (Mapa 1). Tem cerca de 300 membros, entre homens e mulheres com idades de 17 a 60 anos.

\section{Mapa 1 - Localização do município de Matinhos, no estado do Paraná:

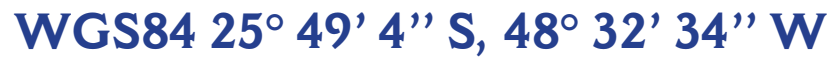
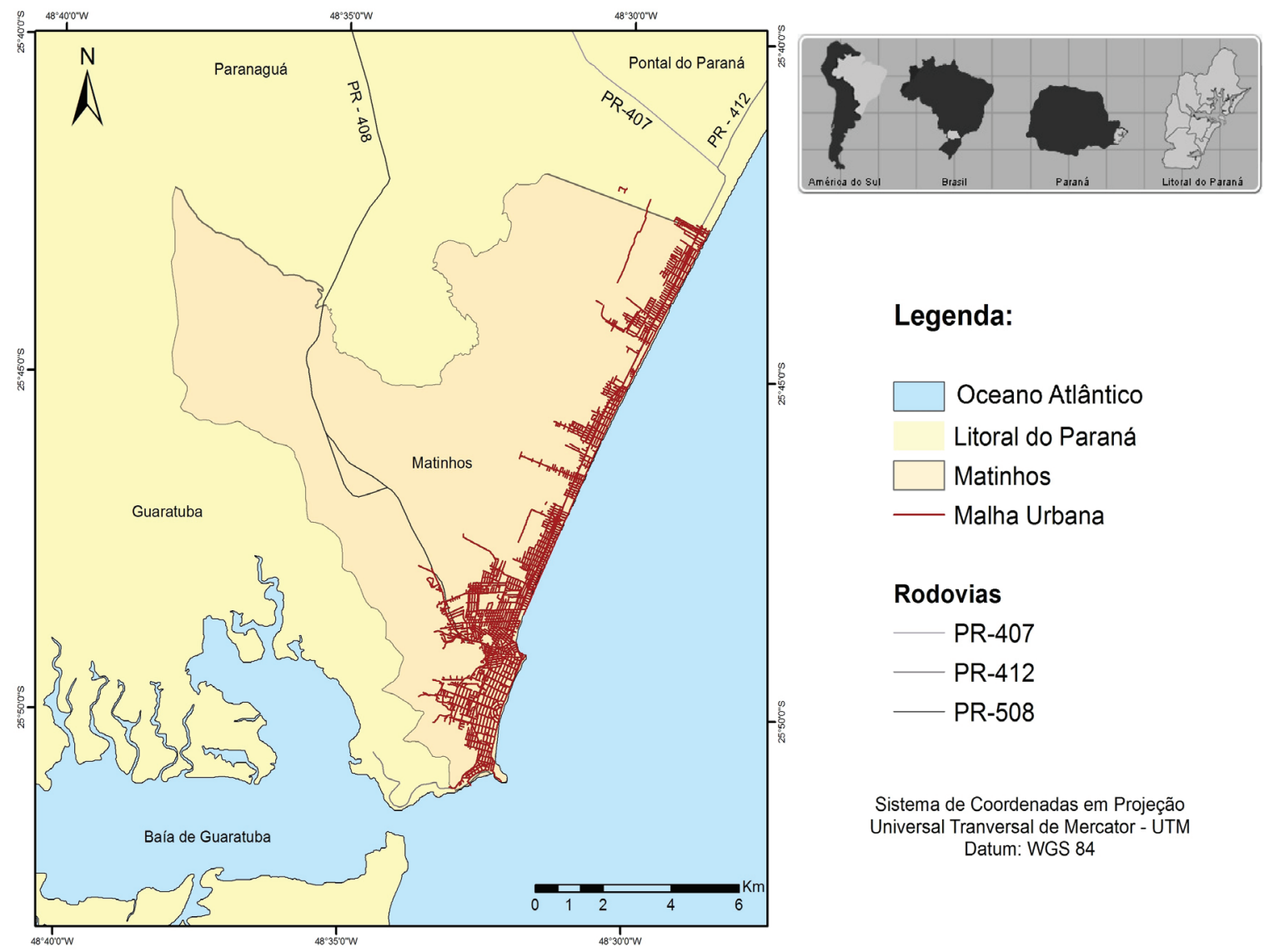

Legenda:

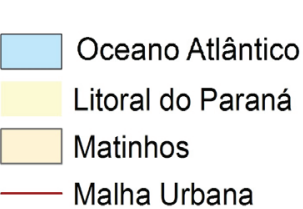

\section{Rodovias}

- PR-407

PR-412

PR-508

Sistema de Coordenadas em Projeção Universal Tranversal de Mercator - UTM Datum: WGS 84

organização: Ana Clara Geraldi Costa. (Mapa criado no programa gvSIG - Sistema de Informação Geográfica Livre.)

De acordo com Andreoli (2007), a valorização imobiliária e o aumento da população no litoral fizeram com que a maioria dos pescadores, desta região, vendesse suas propriedades ou posses e passasse a morar distante da orla. Outros que tinham residência na faixa que pertence à marinha foram obrigados a abandonar a área e receberam em troca lotes da prefeitura municipal. 
Constata-se esse fato nessa comunidade de pesca artesanal de Matinhos: seus integrantes não moram no lugar onde ficam as embarcações, os apetrechos de pesca, a colônia e o Mercado Municipal (Figura 1), mas em bairros espalhados pela cidade, algumas vezes distantes das atividades pesqueiras.

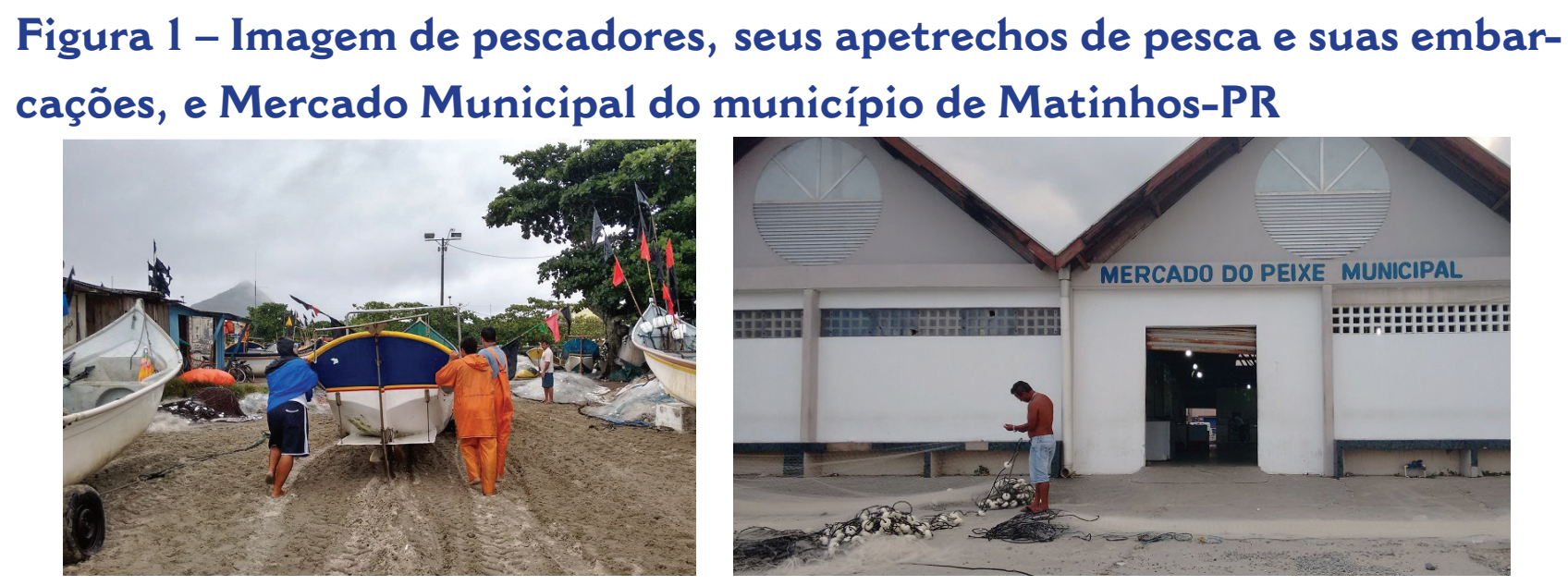

fotos: Ana Clara Geraldi Costa, 2014.

Por não residirem no local, alguns pesquisadores, como Andreoli (2007), podem não dizê-los comunidade, mas, nesse estudo, usa-se esse termo, pois esses trabalhadores passam a maior parte de seu tempo nesse lugar arrumando redes, confeccionando canoas, batendo papo, limpando e vendendo os peixes no Mercado Municipal, entre outras coisas. Além disso, os próprios integrantes se autodenominam "comunidade".

Sendo assim, acreditamos que mais do que existir em um território achado, doado, conquistado, apropriado e tido como um lugar natural e social legitima de existência de uma comunidade de ocupação, o que qualifica uma comunidade tradicional é o fato de que ela se tornou legitima através de um trabalho coletivo de socialização da natureza (Brandão; Leal, 2012).

Nesse sentido, os autores ressaltam que comunidade é o lugar humano da vida. Desde tempos antigos foi e segue sendo o lugar social arrancado da natureza, ou nela encravado, em que pessoas, familias e rede de parentes e comunheiros, reúnem-se para viver suas vidas e dar, entre palavras e gestos, um sentido a ela. Em termos modernos, a comunidade é o lugar da escolha: "é a associação, quanto mais livre e auto-assumida melhor - de pessoas que se congregam para serem o que desejam ser nela” (Brandão; Leal, 2012, p. 77).

$\mathrm{Na}$ comunidade de pesca de Matinhos, muitos de seus membros fazem parte da mesma familia. A saída para o mar é um privilégio essencialmente masculino, mas as mulheres participam desse universo limpando e vendendo os peixes no Mercado Municipal e também trabalham por conta própria nas pequenas lanchonetes, que ali se instalaram para atender a comunidade pesqueira. Quando voltam da escola, as crianças ficam na companhia das mães e, à medida que ficam mais velhos, os meninos acompanham os pais. Observa-se, portanto, que o ambiente é bastante familiar.

De acordo com Cardoso (1999), a pesca artesanal representa uma modalidade de uso do espaço. Sua especificidade reside na articulação entre os meios aquático e terrestre, sendo que o primeiro comporta os processos de apropriação da natureza e o segundo significa os espaços da realização do pescado como mercadoria. 
Os pescadores pescam com canoas de fibra a motor e usam redes de náilon; chamam suas práticas de cerco, fundeio e caceio, ${ }^{5}$ como outras comunidades pesqueiras. Apesar de terem adotado novas tecnologias como as canoas a motor, anteriormente citada, eles podem ser considerados tradicionais justamente por essa característica familiar e por muitos desses pescadores serem netos de pescadores e por terem aprendido a arte da pesca com seus antepassados por meio da prática oral (Diegues, 1983; Andreoli, 2007).

Além disso, Andreoli (2007) caracteriza esses pescadores como tradicionais pela simplicidade da tecnologia, baixo custo da produção e pequena produção mercantil, visando principalmente o próprio sustento através de equipes de trabalho formadas por relações de parentesco e compadrio, sem vínculo empregatício entre a tripulação e o mestre dos barcos.

No âmbito deste estudo é importante destacar que esses pescadores passam hoje por alguns conflitos ambientais, que vêm dificultando a continuidade da pesca e muitas vezes a tornando inviável. Entre eles, podemos citar o conflito com a pesca industrial, que com suas redes de arrasto pescam peixes de todas as espécies e tamanho, e ainda estragam as redes dos pescadores artesanais, e os conflitos em decorrência do estabelecimento de leis ambientais, como a milha náutica ${ }^{6}$ e 0 recente episódio da criação do Parque Nacional Marinho das Ilhas dos Currais (Mapa 2).

\section{Mapa 2 - Localização do Parque Nacional Marinho das Ilhas dos Currais. Coordenadas S 25॰44'098" W 48॰21'752"}
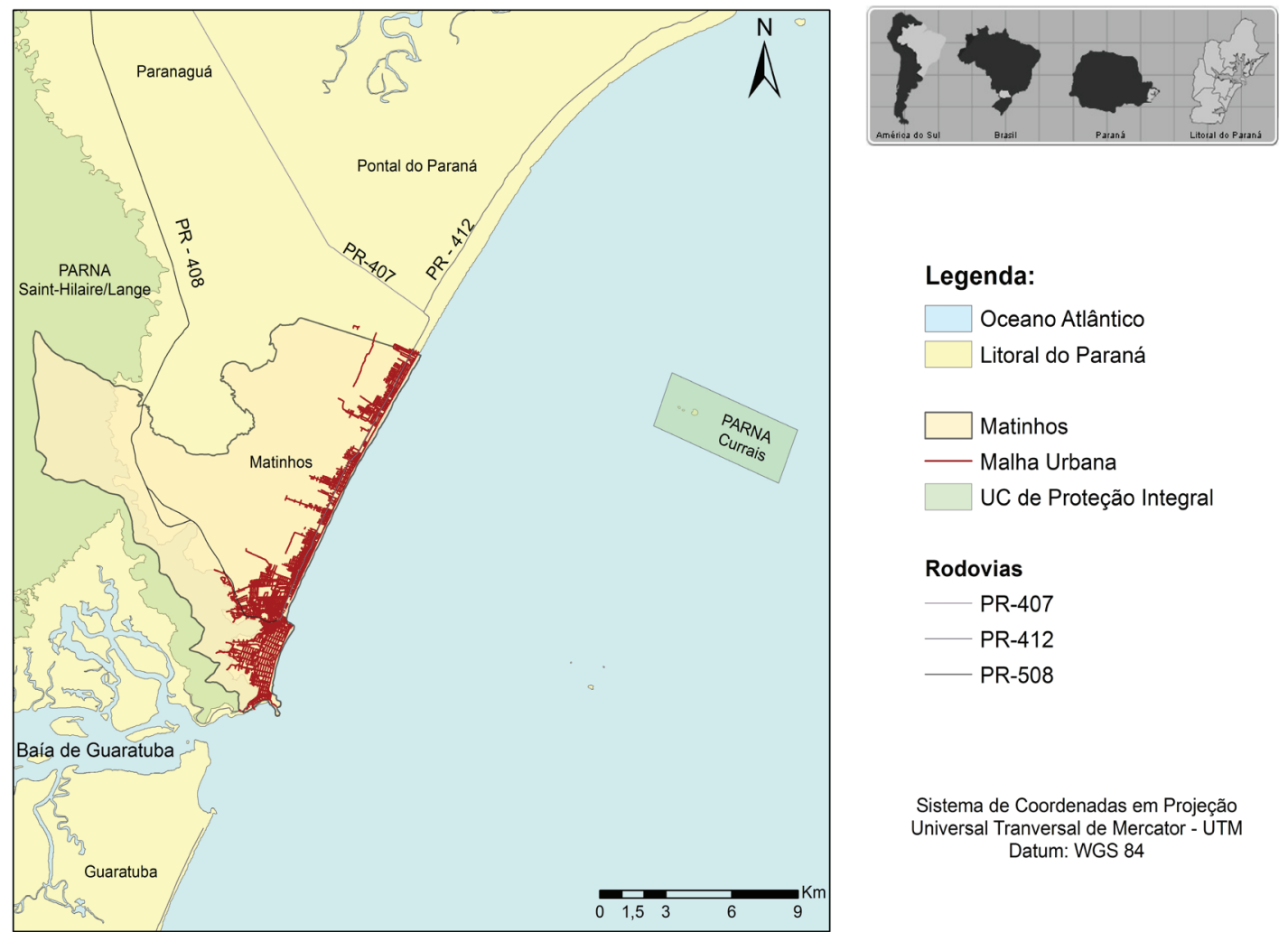

\section{Legenda:}

Oceano Atlântico

Litoral do Paraná

Matinhos

Malha Urbana

UC de Proteção Integral

\section{Rodovias}

PR-407

- PR-412

- PR-508

Sistema de Coordenadas em Projeção

Universal Tranversal de Mercator - UTM Datum: WGS 84

organização: Ana Clara Geraldi Costa. (Mapa criado no programa gvSIG - Sistema de Informação Geográfica Livre.)

5 Na comunidade de pescadores de Matinhos, praticam-se basicamente três tipos de pesca: cerco, fundeio e caceio. No cerco, os pescadores avistam um cardume de peixes e cercam-no com "redes altas" (20-25 m). No fundeio, fincam-se no mar ferros que ficam de um dia para outro. Finalmente, no caceio, solta-se a rede no mar e se a deixa ao sabor da correnteza.

6 No Brasil, várias leis regulamentam a pesca; entre elas, as que a probem até uma distância da costa - as chamadas de milhas náuticas. No estado do Paraná, essa distância é de uma milha, ou cerca de $1.852 \mathrm{~m}$. No entanto, essas milhas não correspondem à realidade da pesca local, pois os pontos de pesca do camarão, por exemplo, costumam ficar antes dessa distância. 
O estabelecimento do referido parque em 2013 vem impedindo o uso e acesso consuetudinário às águas e, por conseguinte, à tainha (Liza dumerili [Steindachner, 1870]) e à cavala ${ }^{7}$ (Scomber japonicus [Linnaeus, 1758]), que eram pescadas principalmente nos meses de maio, junho, julho e agosto. Somado a isso, o processo da criação do Parque, assim como outras leis ambientais, tem acirrado os conflitos latentes e deixado um sentimento de que falta consulta pública para o estabelecimento de leis ambientais, que são criadas sobretudo de maneira top-down, ou seja, de cima para baixo.

A criação de UC precisa passar por consulta pública com ampla participação dos setores envolvidos para definir localização, dimensão e limites da UC, e de debates sobre a categoria a ser adotada (MMA, 2004). No entanto, os pescadores artesanais afirmam não ter participado de nenhuma reunião. De acordo com o presidente da colônia:

O que fica intrigado na nossa comunidade é que nós... E estou à frente da colônia faz quase 10 anos e não conhecia, não tinha ideia do projeto da ilha ser um parque... Então, pegou nós de contrapé. Ninguém conhecia isso (Presidente da colônia Z4 de pescadores artesanais de Matinhos).

Outra alegação dos pescadores é que o parque tem por finalidade proteger os ecossistemas, os ambientes marinhos e principalmente as aves. Mas, em quase 200 anos de pesca nesses limites, poucas foram as mudanças e transformações ocorridas na paisagem, na percepção ambiental desses sujeitos. Eles alegam ainda que nunca causaram nenhum dano às espécies e que os únicos peixes que pescam são de curso. Portanto, não entendem a relação entre a pesca e a continuidade de vida e reprodução dessas espécies.

Além disso, os pescadores afirmam que o delimitado pela criação do Parque era usado tradicionalmente por seus ancestrais, que inclusive possuíam uma casa de uso coletivo onde salgavam os pescados sem causar nenhuma interferência ou impacto negativo à natureza. Assim, reivindicam o livre acesso e o uso desse espaço tradicionalmente ocupado por seus ancestrais e que foram passados de geração em geração:

Gerou um impacto social, sim, porque nós não podemos mais pescar lá e nós temos isso como uma área de pesca durante alguns meses fortes da economia do município. Enfim, isso vai prejudicar a economia. Tanto como o social, o econômico e o cultural. Na verdade, porque nós temos aquela itha do pessoal, dos ancestrais, que usavam aquela ilha pra salgar peixe, iam a remo lá, né? E nem por isso foi depredada a itha, de maneira alguma, até porque a ilha está intacta até hoje (Pescador Pl, 49 anos).

Esses pescadores são dotados de percepção conservacionista, como também observado por Andreoli (2007), não questionam a criação de uma unidade de conservação com o objetivo de proteger e conservar um bem natural. $\bigcirc$ discurso desses sujeitos apresenta elementos favoráveis à criação da unidade de conservação nas Ilhas dos Currais, ou seja, eles reconhecem a importância de se preservar esse espaço; apenas criticam o modo da concepção:

7 A tainha e a cavala são pescadas por cerco nos limites das três ilhas que compõem os Currais. Os pescadores avistam cardumes dessas espécies e os cercam com malhas 11 e 12 (malhas grandes, que só pescam peixes de mais de 1,5kg). Além disso, de acordo com os pescadores, esses peixes são de época e de curso, isto é, só passam por ali no inverno e logo seguem para o norte. 
Na verdade, nós, pescadores, não somos contra, de maneira alguma, à criação do parque ou de áreas que venham preservar, até porque dependemos do mar pra pesca, porque o mar produz pra nós sobreviver (Pescador Pl, 49 anos).

Ao estudar a relação entre os pescadores artesanais de Matinhos e a natureza, Andreoli (2007, p. 99) também observou que estes, por depender diretamente dela - no caso, o mar -, observam-na diariamente e a conhecem profundamente. Como ressalta a autora, "fica claro que os pescadores possuem um amplo e especializado conhecimento sobre o ambiente em que trabalham". Além disso, os conhecimentos tradicionais que esses pescadores trazem em sua bagagem profissional, são de grande utilidade sob o ponto de vista da contribuição para a conservação da natureza.

Nesse ponto, os pescadores ressaltam que muitas leis são redigidas por pessoas que não conhecem sua realidade ou o dia a dia da pesca:

Quando fazem essas leis aí, eles não consultam o pescador, né?, que é sempre o principal afetado por essas leis aí... A lei sai, e a gente só fica sabendo depois. Eu acho que isso dai devia ser conversado com a comunidade toda, porque atrapalha a vida da gente, né? De pesca, quem conhece é o pescador... Quem faz a lei não pesca (Pescador P5, 54 anos).

Do mesmo modo, eles reivindicam maior participação no estabelecimento de leis ambientais como essa, uma vez que estão na região há décadas, conhecem as dinâmicas naturais desse ecossistema e sabem até que ponto determinada proibição afetará o resto da comunidade.

Com essas e outras proibições, segundo eles "se sentem massacrados" por um sistema que os abandona, oprime e os destitui de direitos. Segundo eles, a arte da pesca está sendo afetada e com isso parte da cultura está se perdendo. Nesse contexto, Capellesso e Cazella (2011), ressaltam que é cada vez mais comum, por exemplo, os jovens não pensarem em seguir a profissão, justamente pelas dificuldades enfrentadas, o abandono a que foi relegado a pesca artesanal, essa situação é observada inicialmente com os filhos destes pescadores, que passam a atuar em outras atividades econômicas.

De acordo com os pescadores, eles já sofrem bastante com a pesca industrial que vêm diminuindo expressivamente o estoque pesqueiro na região. Os limites que compreendem hoje o parque seriam uma espécie de refúgio para eles, pois nestes espaços, os barcos grandes da pesca industrial não conseguem entrar para danificar suas redes.

Diferentemente dos novos movimentos sociais ora citados, essa comunidade não utiliza ainda em seu discurso, a palavra território para expressar este espaço geográfico e suas inter-relações entre os meios físico, biológico, social e cultural. Porém é possível perceber que os limites que hoje pertencem ao parque fazem parte de sua vida tradicional não somente pelo aspecto econômico, mas principalmente porque ela representa a reprodução simbólica, material e essencial para a continuidade social e cultural dessas familias.

Além disso, os pescadores ressaltam que os peixes antes capturados nestes limites serviam, não só para a sobrevivência dessas familias, mas também geravam impactos positivos para a cidade, já que a pesca é uma das atividades principais e mais tradicionais do município. 
Segundo eles, quando a pesca vai mal, toda a cidade vai mal, inclusive suas relações sociais. Afirmam ainda que toda a comunidade de pesca espera pelos meses da tainha, pois sabe que este período faz parte da cultura local e acarreta muitos benefícios econômicos.

Contudo, a proibição do usufruto dos pescados na região é um risco para a segurança econômica e, por conseguinte sobrevivência dessas familias, pois muitas delas acessaram os recursos do Programa Nacional de Fortalecimento da Agricultura Familiar (Pronaf) para a aquisição de apetrechos de pesca, renovação e/ou reforma de suas canoas, com a restrição muitos deles não conseguirão honrar o pagamento destes empréstimos.

Posto isso, Cruz (2013) adverte que se trata de lutas pelo direito à territorialidade, que é fundamental na reprodução dos modos de vida tradicionais, pois o território é para essas populações, simultaneamente os meios de subsistência, de trabalho, produção e os meios de produzir os aspectos materiais das relações sociais. $\bigcirc$ território constitui-se então um abrigo e como fonte de recurso materiais ou meio de produção, ao mesmo tempo elemento fundamental de identificação ou simbolização de grupos através de referenciais espaciais.

De acordo com Milton Santos (2006), o território não é apenas o resultado da superposição de um conjunto de sistemas naturais e um conjunto de sistemas de coisas criadas pelo homem. $\bigcirc$ território é o chão e mais a população, isto é, uma identidade, o fato e o sentimento de pertencer àquilo que nos pertence. Em síntese, é a base do trabalho, das trocas materiais e espirituais.

Já para Haesbaert (2014), o território nesse caso envolve uma dimensão simbólica/ cultural através de uma identidade territorial atribuída pelos grupos sociais, como forma de "controle simbólico" sobre o espaço onde vivem (sendo também uma forma de apropriação), e uma dimensão mais concreta, de caráter político-disciplinar; a apropriação e ordenação do espaço como forma de domínio e disciplinarização dos indivíduos.

Nesse sentido, observa-se que esses pecadores artesanais têm na base de seus bens pesqueiros elementos fundamentais para a sua reprodução socioeconômica e cultural. $\bigcirc$ território "Currais" representa para os pescadores uma herança de seus ancestrais. Eles valorizam este espaço, entre outras questões, pela história familiar e comunitária.

Como lembra Svampa (2011), não se trata exclusivamente de uma disputa em torno dos recursos naturais, mas sim uma disputa pela construção de um tipo de territorialidade baseado na proteção desse patrimônio, que consegue ser para eles um bem natural, social e cultural. No caso desse locus, trata-se ao mesmo tempo do direito à participação nesse território e da continuidade de sua cultura.

Frente a estes processos, os pescadores se defrontam com um amplo campo de embate, articulam suas práticas e formas de resistência ou aceitação. A politização do movimento de pescadores aparece como uma das ações ultimadas por estes sujeitos sociais nas discussões das questões que envolvem seus espaços de vida, moradia, trabalho, seu espaço geográfico e seus territórios (Cardoso, 1999).

\section{Considerações finais}

À luz do que foi exposto, é possível concluir que existe uma relação direta entre os processos de desenvolvimento e os conflitos ambientais que eclodiram nas últimas décadas. As estratégias de desenvolver - sobretudo economicamente - o país não foram, na maioria das 
vezes, compatíveis com os desejos e demandas da grande massa subalternizada, principalmente com os dos povos e comunidades que, ao longo de sua existência, desenvolveram modos de vida e produção singulares, em harmonia com a natureza.

Isso fica mais claro quando se observam o panorama histórico da mobilização social e os discursos desses atores. Eles não reivindicam apenas garantias de sobrevivência material, como as necessidades básicas de se alimentar ou vestir, ou ainda um trabalho digno dentro do sistema capitalista. Suas lutas e discursos expressam o desejo de autonomia e, sobretudo, a garantia de continuidade de suas práticas que, nesse universo, envolvem o uso e o acesso consuetudinário aos bens naturais, que o capitalismo insiste em chamar de "recursos naturais".

No caso relatado dos pescadores artesanais do município de Matinhos, essa garantia é relativa ao acesso a um espaço tradicional de pesca que hoje é um parque. Vale ressaltar, contudo, que a criação dessa unidade é de 2013 e que, segundo o Snuc, os responsáveis por sua gestão têm até cinco anos para preparar o Plano de Manejo e formar seu Conselho Consultivo.

Este artigo ressalta o conflito que se instalou no momento da criação do Parque, que, de acordo com os pescadores, não contou com a participação da comunidade de pesca artesanal do município. Seu discurso sobre esse território é, entre outras coisas, pela participação e continuidade do uso e do acesso aos bens pesqueiros.

Os dados coletados se ativeram ao discurso dos pescadores sobre a criação dessa unidade de conservação. $\bigcirc$ próximo passo será mapear os atores envolvidos nesse processo e seus discursos e os possíveis mediadores desse conflito, pois a criação do Plano de Manejo e a formação do Conselho dessa unidade de conservação ainda estão em andamento.

\section{Referências}

ANDREOLI, V. M. Natureza e pesca: um estudo sobre os pescadores artesanais de Matinhos-PR. 2007. Dissertação (Mestrado em Sociologia) - Setor de Ciências Humanas, Universidade Federal do Paraná, Curitiba, 2007. Disponível em: <http://www.pgsocio. ufpr.br/docs/defesa/dissertacoes/2007/VANESSAMARION.pdf>. Acesso em: 20 nov. 2014.

BRANDÃO, C. R. Acumulação permanente e desenvolvimento capitalista no Brasil contemporâneo. In: ALMEIDA, A. W. B. (Org.). Capitalismo globalizado e recursos territoriais. Rio de Janeiro: Lamparina, 2010. p. 39-69.

BRANDÃO, C. Territórios com classes sociais, conflitos, decisão e poder. In: ORTEGA, A. C.; ALMEIDA Filho, N. A. (Org.). Desenvolvimento territorial, segurança alimentar e economia solidária. Campinas: Alínea, 2007. p. 1-25.

BRANDÃO, C. R; LEAL, A. Comunidade tradicional: conviver, criar resistir. Revista da ANPEGE, v. 8, n. 9, p. 73-91, jan./jul. 2012.

CAPELLESSO, A. J.; CAZELLA, A. A. Pesca artesanal: entre crise econômica e problemas socioambientais: estudo de caso nos municípios de Garopaba e Imbituba (SC). Ambiente $\mathcal{E}$ Sociedade, v. XIV, n. 2, p.15-33, jul./dez. 2011. 
CARDOSO, E. S. Geografia e pesca: contribuições para uma análise de conjunto. Boletim Paulista de Geografia, São Paulo, n. 76, p. 85-100, dez. 1999.

CRUZ, V. C. Das lutas por redistribuição de terras às lutas pelo reconhecimento de territórios. Uma nova gramática das lutas sociais? In: ACSELRAD, H. (Org.). Cartografia social, terra e território. Rio de Janeiro: IPPR/UFRJ, 2013. p. 119-176.

DIEGUES, A. C. Saberes tradicionais e biodiversidade no Brasil. Brasilia: MMA/ São Paulo: USP, 2001.

DIEGUES, A. C. Pescadores, camponeses e trabalhadores do mar. São Paulo: Ática, 1983.

ESCOBAR, A. El postdesarrollo como concepto y práctica social. In: MATO, D. (Org.). Políticas de economía, ambiente y sociedad en tiempos de globalización. Caracas: Facultad de Ciencias Económicas y Sociales, Universidad Central de Venezuela, 2005. p. 17-31.

ESTEVA, G. Los quehaceres del día. In: MASSUH, G. Renunciar al bien común: extractivismo y (pos) desarrollo en América Latina. Buenos Aires: Mardulce, 2012. p. 237-281.

FURTADO, C. O mito do desenvolvimento econômico. 6. ed. Rio de Janeiro: Paz e Terra, 1983.

GROSFOGUEL, R. Para descolonizar os estudos de economia política e os estudos pós-coloniais: transmodernidade, pensamento de fronteira e colonialidade global. Revista Crítica de Ciências Sociais, Coimbra, n. 80, p. 115-147, mar. 2008.

HAESBAERT, R. O mito da desterritorialização: do fim dos territórios à multiterritorialidade. 8. ed. Rio de Janeiro: Bertand Brasil, 2014.

MACAS, L. El SumakKawsay. In: HIDALGO-CAPITÁN, A. L.(Org). Antología del pensamiento indigenista ecuatoriano sobre SumakKawsay. Huelva y Cuenca: Cim y Pydlos, 2014. p. 179-192.

MEDEIROS, R. Evolução das tipologias e categorias de áreas protegidas no Brasil. Ambiente $\boldsymbol{E}$ Sociedade, v. IX, n. 1, p. 41-64, jul./dez. 2005.

MMA. MINISTÉRIO DO MEIO AMBIENTE. Áreas protegidas. Brasília: MMA, 2004. v. 2: Gestão Participativa do Snuc.

SANTOS, M. Por uma outra globalização: do pensamento único à consciência universal. 13. ed. Rio de Janeiro: Record, 2006.

SOUZA, M. L. de. Mudar a cidade: uma introdução crítica ao planejamento e gestão urbanos. Rio de Janeiro: Bertrand Brasil, 2002.

SVAMPA, M. Extractivismo neodesarrollista y movimientos sociales. ¿Un giro ecoterritorial hacia nuevas alternativas? In: LANG, M.; MOKRANI, D. (Org.). Más allá del desarrollo. Quito: Fundación Rosa Luxemburgo/AbyaYala, 2011. p. 185-216. 
VARGAS, G. M. Conflitos sociais e socioambientais: proposta de um marco teórico e metodológico. Sociedade E Natureza, Uberlândia, n. 19, v. 2, p. 191-203, 2007.

ZHOURI, A.; LASCHEFSKI, K. Desenvolvimento e conflitos ambientais: um novo campo de investigação. In: (Org.). Desenvolvimento e conflitos ambientais. Minas Gerais: Editora da UFMG, 2010. p. 11-33.

ZIBECHI, R. De los movimientos a las organizaciones. In: Contrainsurgencia y miseria: las políticas de combate a la pobreza en América Latina. México, DF: Pez en el Árbol, 2010. p. 47-76. 